\title{
O CENÁRIO DA FORMAÇÃO SUPERIOR EM GASTRONOMIA NO BRASIL: Uma reflexão da oferta
}

\author{
THE SCENARIO OF SUPERIOR TRAINING IN GASTRONOMY IN BRAZIL: \\ a reflection of supply
}

\section{EL ESCENARIO DE LA FORMACIÓN SUPERIOR EN GASTRONOMÍA EN BRASIL: una reflexión de la oferta}

\author{
Francisco Antônio dos Anjos ${ }^{1}$ \\ Sílvia Regina $\mathrm{Cabral}^{2}$ \\ Regina Celia Linhares Hostins ${ }^{3}$
}

\begin{abstract}
Resumo: A expansão da formação profissional superior na área de gastronomia no país é uma realidade. Este artigo demonstra o mapa da oferta de cursos superiores na área: modalidades, graus e respectivas localizações geográficas na última década. Utilizou-se a pesquisa de caráter exploratório, de base documental, cujas fontes foram o Portal e-Mec do Ministério da Educação, de acesso público, e as páginas online dos cursos. Após este levantamento, elaborou-se uma ficha para a validação das informações com os gestores elou coordenadores dos respectivos cursos. Como resultado, obteve-se 187 cursos cadastrados, sendo, no primeiro filtro, confirmadas as informações de 138 cursos. Buscou-se no segundo filtro, confirmar nas páginas online a oferta ou não destes cursos no período de vestibular e outros processos seletivos $\$ 2016$. Identificou-se que, em 2016, foram ofertados 151 cursos, sendo 137 na modalidade presencial - 128 superiores de tecnologia e nove bacharelados - e 14 superiores de tecnologia na modalidade a distância, com predominância de oferta nas instituições privadas, com e/ou sem fins lucrativos. A distribuição geográfica destes dá-se, predominantemente, nas regiões sul (bacharelados) e sudeste (superiores de tecnologia) e, em menor proporção, nas demais regiões do país.
\end{abstract}

Palavras-chave: Ensino superior; Formação Profissional; Gastronomia; Restauração Gestão em serviços.

\footnotetext{
Abstract: The expansion of the superior professional qualification in the Gastronomy area in Brazil is a reality. This article shows the map of the offer of college education in the area: modalities, degrees and geographic locations, in the last decade. It was used exploratory and document based research, whose sources were the e-Mec Portal of the Brazilian Ministry of Education, and the Course's online pages. After this survey, a form was prepared for the

${ }^{1}$ Professor e Pesquisador da Universidade do Vale do Itajaí - UNIVALI; coordenador do Programa Lato e Stricto Sensu em Turismo e Hotelaria. É o atual Diretor-Presidente da Assoc. Nacional de Pesquisa e Pós-Graduação em Turismo e lidera o grupo de pesquisa PLAGET\UNIVALI. anjos@univali.br

${ }^{2}$ Mestre em Turismo e HotelarialUNIVALI. Coordena os cursos de Graduação Gastronomia e o curso de Turismo e HotelarialUNIVALI; Doutoranda; Professora e Pesquisadora no grupo PLAGET do Programa de Doutorado da UNIVALI. silviacabral@ univali.br

${ }^{3}$ Doutora em Ciências da Educação; realizou o Pós-doutorado no Institute off Education, University of London, no campo da Sociologia da Educação; professora e pesquisadora programa de Pós-GraduaçãolUNIVALI e coordena o grupo de Pesquisa pelo CNPq e CAPES. reginalh@univali.br
} 
validation of the information with the managers and / or coordinators of the respective courses. As a result, 187 registered courses in Brazil were obtained, and in the first filter, the information of 138 courses was confirmed. In the second filter, it was sought to confirm in the online pages the offer or not of these courses in the period of entrance exam and other selective processes in 2016. It was identified that in 2016, 151 courses were offered, which 137 in the presential modality, - 128 technology majors and nine bachelor degrees - and 14 technology majors in the distance modality, with predominance of offer in private institutions, profitable or not. The geographical distribution of these Courses occurs predominantly in the south (bachelor) and southeast (higher technology) regions and, to a lesser extent, in the other regions of the Brazil.

Key words: Higher education; Professional qualification; Gastronomy; Food Services, Service management.

Resumem: La expansión de la formación profesional superior en el área de gastronomía en el país es una realidad. En este artículo se presenta el mapa de la oferta de cursos superiores en el área: modalidades, grados y respectivas localizaciones geográficas en la última década. Se utilizó la investigación de carácter exploratorio, de base documental, cuyas fuentes fueron el Portal eMec del Ministerio de Educación, de acceso público, y las páginas en línea de los cursos. Después de este levantamiento, se elaboró una ficha para la validación de las informaciones con los gestores y los coordinadores de los respectivos cursos. Como resultado, se obtuvo 187 cursos registrados, siendo, en el primer filtro, confirmadas las informaciones de 138 cursos. Se buscó en el segundo filtro, confirmar en las páginas en línea la oferta o no de estos cursos en el período de vestibular y otros procesos selectivos $\backslash 2016$. Se identificó que en 2016 se ofrecieron 151 cursos, siendo 137 en la modalidad presencial - 128 superiores de tecnología y nueve bachilleratos - y 14 superiores de tecnología en la modalidad a distancia, con predominio de oferta en las instituciones privadas, con y / o sin con fines de lucro. La distribución geográfica de estos se da, predominantemente, en las regiones sur (bachilleres) y sureste (superiores de tecnología) y, en menor proporción, en las demás regiones del país.

Palabras clave: Enseñanza superior; Formación profesional; Gastronomía; Restauración Gestión en servicios.

A gastronomia vem consolidando-se como uma importante área de desenvolvimento econômico, cultural e turístico. Para muitos municípios, esta atividade se destaca como o principal produto e/ou oferta turística e, para outros, representa relevante atrativo. Essa forte expansão, por consequência, evidencia também a necessidade de uma evolução no campo da pesquisa e da produção do conhecimento na área, como expressão de um campo de atuação que busca uma formação profissional mais abrangente e consistente do ponto de vista conceitual, metodológico e tecnológico. 
É sob esse prisma que se justifica a realização deste estudo, que tem como propósito mapear a oferta do ensino superior em gastronomia no Brasil e identificar as principais vertentes orientadoras dessa formação quanto às modalidades (presencial ou a distância), graus (sequencial, tecnólogo ou bacharel) e localização geográfica. Ele oferece um panorama da inserção e consolidação dessa área no campo da educação superior, notadamente na presente década, e contribui para reflexões sobre, por um lado, as potencialidades de fortalecimento da área no campo da pesquisa e produção do conhecimento sistematizado e, por outro, as consequências da oferta desenfreada de cursos com perfis de formação aligeirados, causando uma saturação de profissionais no mercado e uma desvalorização da formação e da atuação na área.

Trata-se de um recorte de uma pesquisa mais ampla, desenvolvida em nível de doutorado, na qual se investiga "A formação superior em gastronomia no Brasil e Portugal: políticas, perfis profissionais e práticas curriculares”, do programa de Pós-Graduação Stricto Sensu em Turismo e Hotelaria da Universidade do Vale do Itajaí, com apoio da Coordenação de Aperfeiçoamento de Pessoal de Nível Superior (CAPES) - Programa Ciências sem Fronteiras.

A Gastronomia trata o alimento como forma de arte e seus referenciais estão usualmente sustentados em valores imateriais, vinculados às experiências emocionais vividas pelas pessoas. Num país constituído por ampla diversidade cultural, reconhecido por seus espaços e possibilidades de experiências sensoriais e simbólicas, voltado para a oferta de serviços diferenciados e preparações elaboradas com variedade de sabores, a formação de profissionais altamente qualificados torna-se exigência básica na área.

A autenticidade dos alimentos, o alimento como cultura, a gastronomia e a cultura regional, as práticas alimentares, o desenvolvimento da restauração, a inovação e a criatividade, a gastronomia e a hospitalidade, a força do trabalho na área, a interdisciplinaridade, as ideologias e as culturas são temas discutidos nos referenciais filosófico, antropológico, sociológico, científico e econômico, orientadores dos estudos na área, notadamente, no meio acadêmico.

Apesar das pesquisas na área da gastronomia serem incipientes, já começam a surgir no cenário e as discussões sobre a formação na área apresentam-se ainda pautadas nas práticas operacionais, nas técnicas culinárias, na prestação dos serviços, nas formas e processos administrativos ou na própria gestão empreendedora. 
A curiosidade, a necessidade de comunicação e a busca contínua por outras conquistas, tem conduzido o homem a ampliar seu universo cultural, desbravar novos mundos, novas culturas e, neste sentido, a gastronomia que historicamente é marca identitária da humanidade, ganha na contemporaneidade um lugar de destaque dada a sua potencial capacidade de oportunizar experiências culturais, afetivas e simbólicas, as quais assumem maior status na atividade turística que se revela mundialmente no campo econômico.

Nos países desenvolvidos, o setor de serviços tem-se destacado na economia, refletida no Produto Interno Bruto (PIB)

[...] países como Alemanha, França, Itália e Reino Unido, pertencentes ao G8, desde o final da década de 1990 apresentavam o setor de serviços com participação acima de $70 \%$ no PIB, ao passo que no Brasil, os serviços representam $67,4 \%$, contra $26,8 \%$ da Indústria e $5,8 \%$ da agropecuária (BRASIL, 2014).

A alimentação do século XXI está nas ruas, nos restaurantes e lanchonetes, nos hotéis, nos shoppings, enfim, num território social que tem contribuído significativamente para a geração de empregos e renda, abrindo portas para o profissional da área.

É, portanto, uma nova tarefa a ser assumida pelas Instituições de Ensino Superior dispostas a enfrentar os desafios de atender tanto a esta demanda, como a própria oferta de profissionais para atuarem na arte da gastronomia que cresce à medida que ganha reconhecimento da sociedade.

Atualmente, as universidades no Brasil, têm uma certa liberdade na organização de suas propostas ou estruturação dos cursos superiores, entretanto, há a obrigatoriedade em atender a Lei de Diretrizes e Bases (LDBEN196), as Diretrizes Curriculares Nacionais para os cursos de graduação e o Catálogo Nacional dos Cursos Superiores de Tecnologia do Ministério da Educação (MEC), os quais expressam as políticas para o ensino superior.

De acordo com o portal do Ministério da Educação (BRASIL, 2015), o quadro atual de oferta no ensino superior no segmento de alimentos, são denominados: Alimentos, Ciências dos Alimentos, Ciências e Inovação do Alimento, Ciências e Tecnologia de Alimentos, Desenvolvimento Rural e Segurança Alimentar, Engenharia de Alimentos, Química de Alimentos e Gastronomia, nos graus: Sequencial, Tecnologia e Bacharelado.

Por tratar-se de um estudo exploratório e de pesquisa de natureza documental, utilizou-se como fonte de dados o portal e-Mec, no qual estão disponíveis (com livre acesso) as informações, 
notadamente os dados de identificação, data de autorização e situação de funcionamento. Também foi considerada como fonte documental as páginas online de cada curso e instituição ofertante. Os dados coligidos foram sistematizados em uma ficha e encaminhada aos gestores elou coordenadores dos respectivos cursos para sua validação e confirmação da oferta.

Em um universo de 187 cursos cadastrados, com autorização de funcionamento do MEC, obteve-se um retorno de 138 cursos, o que representa $74 \%$ de resposta.

Para atender ao objetivo de identificar o número de cursos ofertados, realizou-se como segundo filtro, o acesso às páginas online, no período do vestibular e demais processos seletivos em 2016, dos cursos que não responderam a ficha técnica para confirmar sua oferta. Desse modo, confirma-se que 187 cursos autorizados pelo MEC, 151 foram ofertados no Brasil em 2016, distribuídos em diferentes regiões.

\section{Uma reflexão teórica sobre a formação}

A reflexão sobre a oferta de cursos superiores em gastronomia no Brasil não se resume a mera descrição quantitativa de cursos. Nesse processo de identificação da oferta existente há implícita a configuração do perfil de formação na área, do potencial de crescimento da área no campo da educação superior, do potencial de fortalecimento da profissão no mercado de trabalho e da contribuição da atividade no desenvolvimento econômico, mais precisamente na área de gestão de serviços. Dessa forma, busca-se nesse item discutir os conceitos de gastronomia, restauração e perfil de formação com enfoque nas habilidades e competências, conceitos estes mediados por outros estudos realizados, os quais tem uma aproximação com esse tema.

\section{Do conceito de Gastronomia à gestão}

Ao ouvir as palavras: alimentos Igastronomialrestauração, no primeiro momento, parece tudo muito similar e o pensamento traz a imagem de "comida". De fato, não é de todo um erro, pois, no senso comum, o termo comida pode traduzir o processo que envolve os princípios básicos da necessidade humana de saciar a fome.

Para Santich (2004, p. 15) 
[...] a gastronomia é um conceito escorregadio para definir e explicar. A maioria dos dicionários definem gastronomia em termos de arte e/ou ciência do bem/comer delicado. Esse foco na arte e ciência se traduz, em termos práticos, como habilidade e conhecimento, que se conecta perfeitamente com as origens do termo. O primeiro uso da palavra "gastronomia" foi na Grécia antiga. Gastro refere-se ao estômago e, por extensão de todo o sistema digestivo, a partir da boca, enquanto nomos significa regra ou regulamento. Gastronomia portanto refere-se a regras ou normas a respeito de comer.

Se o conceito de gastronomia em si tem sua complexidade, por abranger as diferentes facetas da relação homem, cultura e alimentação, mais complexo se torna ao considerar a organização da formação de profissionais para atuar nesse campo multifacetado.

Hegarty (2005) em seus estudos sobre ciência culinária e tecnologia discute a complexidade da gastronomia a partir do que chama de um projeto para atender as necessidades de graduados que buscam seguir carreira como especialistas em serviços da alimentação, fornecedores elou restauradores. Ao definir essa área de atuação o autor destaca a necessária articulação entre arte culinária, ciência e gastronomia.

A arte culinária, a ciência e a gastronomia são campos complexos do ser humano, do conhecimento e da atividade, que começa onde a comida começa, na imaginação continua com a seleção, combinação, processamento e distribuição para o consumo prazeroso, nutritivo, e microbiologicamente seguros por indivíduos (gastronomia molecular) e termina com a eliminação do desperdício de alimentos de forma ambientalmente amigável. A essência da culinária rigorosa encontra-se no conhecimento estético e experimental que as expressões sensoriais de estudiosos e profissionais desenvolvem, bem como a excitação emocional, amor, diversão e teatro experiente, enquanto se envolver com o estudo do campo da culinária (HEGARTY, 2005, p. 2).

Nesse sentido, os estudos evidenciam ainda a ciencia culinária e a gastronomia como a utilização do conhecimento científico para tornar melhor os alimentos de consumo humano, colabora com a saúde humana e evita doenças como a obesidade. E, ainda, investiga a educação e as carreiras em ciências culinárias, as tecnologias e as interfaces entre elas.

Santich (2004) alega que, histórica e etimologicamente, que a gastronomia trata do aconselhamento da "arte de viver bem". Estes prazeres tornam o turismo gastronômico, advindo do turismo cultural, uma experiência, em que a industria da hospitalidade tem um papel natural.

Zopiatis (2010) também contribui para pensar a complexidade da área da gastronomia quando apresenta no artigo "É arte ou ciência? Competencias do chef para o sucesso". O artigo 
permea pela dificil profissão do chef na industria da hospitalidade, uma profissão composta pelo dominio científico e de inovação artística, necessitando ainda de competência para a produção culinária como também do gerenciamento. Após sua investigação junto aos chef's de Chipre ( país do médio oriente), sobre quais as competências necessárias para o sucesso da carreira, o resultado apurado apontou para a competência sobre as técnicas específicas de culinária, seguida da competência de gestão de liderança.

Objetivando apresentar os prazeres da mesa, a gastronomia vem conquistando o seu espaço como um segmento cultural, social e econômico. O debate e o interesse da educação profissional no campo da gastronomia têm sido percebidos como um processo evolutivo e multidisciplinar.

Deste movimento, torna-se imprescindível a atividade da restauração que, no entendimento de Krause (2013)

[...] pode ser conceituada como o segmento do setor da alimentação no qual se produz o alimento imediatamente servido ao cliente. $\mathrm{O}$ termo tem origem no vocabulo francês restauration, cujo significado remete a uma atividade que consiste em explorar comercialmente a confecção e a venda ao público de alimentos e bebidas sob a forma de refeições (KRAUSE, 2013, p. 203).

O termo "Restauração", portanto, vem sendo adotado para identificar no mercado da alimentação os alimentos produzidos ou elaborados com base na convergência sabor-aroma-cor e design, envolvendo as técnicas e os serviços da gastronomia, dos mais simples aos mais complexos, aliados ao processo de comercialização, seja ao público turístico, aos autóctones ou aos visitantes.

O setor de alimentos envolve a gastronomia e a restauração, portanto é um segmento que necessita de conhecimento específico de gestão, pois entrega-se ao cliente um conjunto de elementos, alguns mais e outros nada estocáveis, com características intrínsecas que podem ser explícitas ou implícitas para sua satisfação.

Betancourt-Ramirez, Aldana-De-Vega e Gomez-Betancourt (2014, p. 63), em um estudo comparativo entre empresa familiar e não familiar, destacam a concepção de qualidade dos serviços. Para os autores, essa concepção tem caráter filosófico e expressa princípios que são introduzidos na cultura interna da empresa. 
Este conceito foi retomado por muitos autores ao longo do tempo, tendo em conta dois aspectos: o tipo de indústria e o contexto cultural. Como podemos ver, a qualidade do serviço de um Restaurante é um critério, que depende da forma de serviço prestado e do conceito que administra o estabelecimento. Hoje em dia os clientes exigem cada vez mais o cumprimento dos detalhes que tornam mais confortável sua estadia, para o qual se faz necessário assegurar os atributos básicos do serviço como o ambiente, a oportunidade, a cortesia, a higiene, a tangibilidade e a segurança (BETANCOURT-RAMIREZ; ALDANA-DE-VEGA; GOMEZ-BETANCOURT, 2014, p. 64).

O produto "alimento" conta com a agregação dos serviços e obtém a característica da simultaneidade. Ele, por si só, muitas vezes, não é o único produto final e a responsabilidade para que todo o processo resulte num diferencial competitivo deve-se a uma competência administrativa ou de gestão.

A necessidade de formação profissional de excelência torna-se, portanto, imprescindível e, para a área de alimentos, esses profissionais precisam obter uma formação, não apenas da prática da produção do alimento, mas também do amplo campo cultural e afetivo da arte da alimentação e do complexo processo de gestão envolvido nessa atividade de natureza híbrida que se configura tanto como produto como em serviço.

\section{Da formação profissional}

$\mathrm{Na}$ organização de um curso de gastronomia busca-se assegurar a diversidade, a complexidade e a abrangência de conhecimentos para uma formação efetiva do profissional.

As autoras Gesser e Ranchetti (2011) ao tratarem da formação profissional no ensino superior chamam a atenção para os desafios que a atualidade apresenta, por exemplo, a responsabilidade dos educadores atuais em formar profissionais em um tempo em que mudanças ocorrem sucessiva e sistematicamente, e estes, ainda devem estar preparados para suas atuações profissionais neste novo papel.

A competência permite a mobilização e sistematização de conhecimentos para que se possa enfrentar uma determinada situação, uma capacidade de encontrar recursos, no momento e na forma adequada. Ela implica na regularização de conhecimentos e esquemas que se possui 
para desenvolver respostas inéditas, criativas e eficazes, que consiste em ser capaz de indagar, pesquisar, procurar alternativas, enfim ter uma atitude questionadora perante a realidade.

A formação em gastronomia não requer apenas um processo de aquisição de conhecimentos, técnicas ou informações, mas a competência para a aquisição e assimilação de novos padrões e formas de perceber, ser, pensar e agir em torno deste fenômeno complexo que é a alimentação.

A pesquisadora Meng Lei Hu, da Jinwen University of Science and Technology, publicou sua pesquisa no Journal of Hospitality, Leisure, Sport and Tourism Education (2010), cujo o objetivo foi o de investigar e apresentar a importância da competência inovadora para o desenvolvimento culinário.

Para a autora, o estudo da competência é um importante passo para a formação profissional e envolve diferentes concepções. Alguns defendem que os principais componentes da competência são: habilidades, julgamento, atitudes e valores (BIRDIR; PEARSON, 2000, p. 205). Outros autores sugerem que a competência de trabalho é uma característica subjacente de uma pessoa que resulta em desempenho eficaz e/ou superior em um trabalho (BOYATZIS, 1982) $\mathrm{e}$, tem aqueles, que afirmam que a competência requer o trabalho com tarefas, resultados e produtos, incluindo conhecimentos, habilidades e atitudes (Hu, 2010, p. 66).

Unindo o resultado da pesquisa com os modelos de competência, a autora propõe um modelo multidimensional que caracteriza a competência da culinária inovadora, abrangendo inúmeras dimensões, a saber: 1) Cultura - que permite aos chef's adquirirem a capacidade de criar obras de vitalidade; 2) Estética - que alimenta os sentidos e o pensamento das pessoas; 3) Produto - o compromisso de criar produtos inovadores, de sabor original e harmonioso e novos ingredientes e receitas, com perspectivas de mercado; 4) Gestão - o desenvolvimento de processos inovadores, trabalhar com tendências atuais e futuras e com capacidade de gerenciar a informação; 5) Criatividade - capacidade de criar, apresentando o conhecimento da ciência da culinária com uma atitude positiva para o desenvolvimento de novas ideias e otimismo;6) Serviços - compreender a importância da prestação do serviço na contextualização do processo da produção ao atendimento, saber lidar com as pessoas, suas fragilidades e complexidades; e 7) Tecnologia - as competências tecnológicas incluem o conhecimento dos princípios da ciência alimentar, química da cozinha, capacidade de usar a tecnologia para manter os alimentos frescos e uma atitude positiva em relação ao uso de novos equipamentos de cozinha (HU, 2010). 
A autora ainda revela que há um consenso em desenvolvimento, em que a competência inovadora é essencial para o alcance do sucesso de um chef ou do próprio empreendimento. Atuar com a competência inovadora em propostas de treinamento e qualificação ainda é um desafio.

A soma de conhecimentos, experiências, mais o saber como fazer, com a aplicação dos conhecimentos técnicos no exercício profissional, identificar variáveis, compreender fenômenos, relacionar informações, analisar situações/problemas, sintetizar, julgar e correlacionar são reflexos de habilidades.

Em face destes conceitos, identifica-se a relevância da discussão sobre qual o perfil de profissional da gastronomia que se pretende formar, tendo em vista o expressivo crescimento da oferta de cursos nessa área, notadamente no Brasil, oferta essa que, em muitos casos, poderá prevalecer a quantidade em detrimento da qualidade.

\section{Evolução da educação profissional em gastronomia}

A culinária sempre foi uma expressão cultural, passada adiante entre grupos familiares, tarefa de competência das mulheres, pois os homens exerciam outras atividades profissionais. $\mathrm{O}$ ensino da gastronomia como profissão surgiu da evolução do conceito em si.

A primeira escola de gastronomia reconhecida no mundo surgiu em Paris (Le Cordon Bleu), fundada em 1895, destinada a cursos profissionalizantes ligados à culinária e aos serviços de hospitalidade. Apenas na segunda metade do século XX, Le Cordon Bleu se especializou em cursos de graduação e pós-graduação, mas com o objetivo específico em gestão.

Por muitos anos, a aprendizagem da culinária acontecia somente no trabalho. Os jovens imigrantes que precisavam trabalhar aprendiam como ajudantes e, se mostrassem interesse, subiam na carreira.

No Brasil, somente a partir do governo Getúlio Vargas (1937-1945) houve o interesse em desenvolver uma educação mais técnica e profissionalizante, preparando mão de obra para a indústria em expansão.

Nessa época, foram criados: o Serviço Nacional de Aprendizagem Industrial (SENAI), em 1942; e o Serviço Nacional de Aprendizagem Comercial (SENAC), em 1946, para o treinamento de mão de obra especializada. Apesar de oferecer cursos nas mais diferentes áreas, o direcionamento do SENAC foi para a formação de mão de obra. 
O SENAC em São Paulo se tornou referência em cursos na área de serviços e hospitalidades. A instituição foi pioneira ao lançar, em 1951, o curso de especialização para garçons e, em 1957, os primeiros cursos de treinamento e habilitação profissional em hotelaria. Em 1964, deu início aos cursos de Garçom, Cozinheiro, Barman, Porteiro-Recepcionista e Secretário De Administração De Hotéis E Restaurantes, principalmente em São Paulo. Na década de 1970, os cursos eram oferecidos gratuitamente, em regime de internato, para alunos financeiramente carentes e que recebiam uma bolsa-auxílio para estudar.

Os cursos de gastronomia foram implantados somente no final da década de 1990, embora no SENAC em Águas de São Pedro-SP, em 1994, existisse o Curso de Cozinheiro Chef voltado para uma clientela com formação acadêmica. A partir daí os Chef's começaram a se instalar no Brasil, valorizando esta profissão.

Assim, em 1999, surgiram os primeiros cursos superiores no Brasil. Primeiro, o curso de Turismo (bacharelado) com habilitação em Gastronomia, da Universidade do Sul de Santa Catarina, em Florianópolis- SC, posteriormente, o curso Superior de Formação Específica em Gastronomia, da Universidade de Anhembi Morumbi-SP e, no mesmo ano, o curso de Gastronomia, da Universidade do Vale do Itajaí (UNIVALI), em Balneário Camboriú-SC.

O SENAC, que havia lançado o curso de Tecnologia em Hotelaria em 1989, somente iniciou suas atividades no Ensino Superior de Gastronomia no ano 2000, com o curso de Tecnologia, no Hotel Escola Águas de São Pedro (SENAC-SP). O SENAI e SENAC continuam a oferecer a formação operacional na área e, a Gastronomia, se expande por intermédio dos cursos de graduação, além dos cursos de extensão universitária e de pós-graduação (lato sensu), ampliando suas perspectivas de produção do conhecimento por meio do ensino e da pesquisa universitária.

\section{Organização e regulamento dos cursos superiores de gastronomia}

O ensino superior brasileiro é regido pela Lei de Diretrizes e Bases (LDB\1996), envolvendo a graduação e a pós-graduação (Stricto e Latu Sensu). Para o ensino superior, o Título V apresenta os Níveis e as Modalidades de Educação e Ensino - Capítulo IV - Da Educação Superior, sendo que no art. 44, inciso II, define-se que o ensino superior abrangerá: cursos sequenciais; de graduação; de pós-graduação e de extensão. 
Em Gastronomia, há uma distinção bem clara quanto a área de produção dos alimentos, cursos que possuem por objetivo formar profissionais para atuarem na arte da cozinha, na transformação do alimento em comida e/ou na gestão da restauração, denominados cursos de Gastronomia.

Os cursos superiores de Gastronomia cadastrados no portal e-Mec (BRASIL, 2015) apresentam três graus: sequencial, tecnológico e bacharelado, nas modalidades presenciais ou a distância.

$\mathrm{Na}$ formação com grau em Tecnologia, segue as orientações do Catálogo Nacional de Cursos Superiores de Tecnologia (Portaria $n^{\circ} 413$, de 11 de maio de 2016), que tem por objetivo organizar e orientar suas ofertas. De acordo com o Ministério da Educação, o catálogo Nacional de Cursos Superiores de Tecnologia, orienta e regula a oferta dos cursos superiores deste grau e modalidades em cumprimento ao Decreto $n^{0}$ 5.773/06. Ele atua como um guia para referenciar estudantes, educadores e instituições ofertantes, sistemas e redes de ensino, entidades representativas de classes, empregadores e o público em geral.

O Catálogo Nacional de Cursos Superiores de Tecnologia - 2016 é composto por 13 eixos. Os cursos de Gastronomia estão inseridos no eixo Tecnológico Turismo, Hospitalidade e Lazer. Este eixo abriga os Cursos de Tecnologia em Eventos; Tecnologia em Gestão Desportiva e de Lazer; Tecnologia em Gestão de Turismo; Tecnologia em Hotelaria e Tecnologia em Gastronomia.

Neste catálogo, o perfil profissional do curso superior de tecnologia em Gastronomia está assim definido.

Concebe, planeja, gerencia e operacionaliza produções culinárias nas diferentes fases dos serviços de alimentação. Cria preparações culinárias e valoriza a ciência dos ingredientes. Diferencia e coordena técnicas culinárias. Planeja, controla e avalia custos. Coordena e gerencia pessoas de sua equipe. Valida a segurança alimentar. Planeja, elabora e organiza projetos de fluxo de montagem de cozinha. Identifica utensílios, equipamentos e matéria-prima em restaurantes e estabelecimentos alimentícios. Articula e coordena empreendimentos e negócios gastronômicos. Identifica novas perspectivas do mercado alimentício. Vistoria, avalia e emite parecer técnico em sua área de formação. (CATÁLOGO NACIONAL, 2016, p. 152) 
O catálogo define como carga horária mínima do curso $1.600 \mathrm{~h}$ e de infraestrutura é requerida: biblioteca, incluindo acervo específico e atualizado; laboratório de informática, com programas e equipamentos compatíveis com as atividades educacionais do curso; cozinha fria e quente; laboratório de análise sensorial de alimentos; laboratório de bebidas; laboratório de panificação e confeitaria; e restaurante didático.

O documento define ainda como Campo de Atuação: Centros gastronômicos; embaixadas e consulados; empresas de hospedagem, recreação e lazer; hospitais e spas e indústria alimentícia; parques temáticos, aquáticos e cruzeiros marítimos; restaurantes comerciais, institucionais e industriais; catering, bufês e bares; instituições de ensino, mediante formação requerida pela legislação vigente e apresenta como possibilidades de prosseguimento de estudos na pós-graduação na área de Ciência e Tecnologia de Alimentos, entre outras.

Rubim e Rejowski (2013, p. 170), sustentam que:

[...] os cursos de graduação em tecnologia são cursos regulares de educação superior, com foco no domínio e na aplicação de conhecimentos científicos e tecnológicos em áreas específicas de conhecimento relacionado a uma ou mais áreas profissionais. São cursos de curta duração, que visam formar profissionais para atender a campos específicos do mercado de trabalho. O profissional formado recebe a denominação de Tecnólogo e pode dar continuidade ao ensino, cursando a pós-graduação Stricto Sensu e Lato Sensu, como todos os outros cursos de graduação. No entanto, em relação à pós-graduação stricto sensu, as instituições de ensino superior no Brasil podem ou não aceitar tecnólogos.

No grau de Bacharelado, na área de alimentos, a oferta ocorre nos cursos de bacharel em Ciências de Alimentos, Ciências e Inovação do Alimento, Ciências e Tecnologia de Alimento, Desenvolvimento Rural e Segurança Alimentar, Química de Alimentos, Engenharia de Alimentos e Gastronomia.

Esclarece-se que o curso de Gastronomia, na formação bacharelado, não apresenta diretriz curricular específica, no entanto, atende as orientações do Parecer n.: 776/97 e do Parecer n. CNE/CES 67/2003, referencial para as Diretrizes Curriculares Nacionais (DCN) dos cursos de graduação. 


\section{A oferta de cursos de Gastronomia no Brasil}

Em 2016, obteve-se no portal e-Mec 187 autorizações de cursos superiores em Gastronomia (presenciais e a distância), sendo ofertados 151 cursos. A tabela 1 apresenta o cenário nacional.

Tabela 1 - Cursos presenciais e a distância, cadastrados no Portal e-MEC, Brasil

\begin{tabular}{lccccc}
\hline \multirow{2}{*}{ Resultados } & \multicolumn{3}{c}{ Presenciais } & \multicolumn{2}{c}{ À Distância } \\
\cline { 2 - 6 } & Tecn. & Bach. & Sequenc. & Tecn. & Bach. \\
\hline $\begin{array}{l}\text { Cursos Cadastrados Portal E-Mec } \\
=187 \text { Cursos }\end{array}$ & 162 & 10 & 01 & $14^{*}$ & 00 \\
$\begin{array}{l}\text { Cursos não ofertados } \\
\text { Total de cursos ofertados }=\mathbf{1 5 1} \\
\begin{array}{l}\text { Cursos } \\
\hline\end{array}\end{array}$ & 34 & 01 & 01 & 00 & 00 \\
& $\mathbf{1 2 8}$ & $\mathbf{0 9}$ & $\mathbf{0 0}$ & $\mathbf{1 4}$ & $\mathbf{0 0}$ \\
\hline
\end{tabular}

Nota*: Os cursos a distância, neste contexto, foram somados como um curso por estado e por instituição.

Fonte: BRASIL (2016)

Identifica-se na tabela 1 que, no Brasil, a concentração da oferta de cursos de Gastronomia está no grau Tecnologia, seguido por Bacharelado, não havendo mais a oferta de curso Sequencial.

Percebe-se que, no Brasil, a concentração da oferta de cursos de Gastronomia é no grau de Tecnologia, sendo predominante em São Paulo, Paraná, Bahia, Santa Catarina e Rio Grande do Sul. A formação do Bacharelado é ofertada nos estados de São Paulo, Santa Catarina, Bahia, Ceará e Rio de Janeiro.

Quanto à distribuição geográfica, estão distribuídos, conforme demonstra a tabela 2. 
Tabela 2 - Distribuição geográfica e quantitativa

\begin{tabular}{|c|c|c|c|}
\hline Região & UF & Graus & Quantidade \\
\hline \multirow{5}{*}{ Norte } & Amazonas & CSTs & 03 \\
\hline & Pará & CSTs & 04 \\
\hline & \multirow{2}{*}{ Rondônia } & CST & 01 \\
\hline & & CSB & 01 \\
\hline & Tocantins & CST & 01 \\
\hline \multirow{4}{*}{ Centro-Oeste } & Goiás & CSTs & 06 \\
\hline & Mato Grosso & CSTs & 02 \\
\hline & Mato G. do Sul & CSTs & 03 \\
\hline & Distrito Federal & CST & 01 \\
\hline \multirow{4}{*}{ Sul } & Paraná & CSTs & 13 \\
\hline & Rio Grande do Sul & CSTs & 11 \\
\hline & \multirow{2}{*}{ Santa Catarina } & CSTs & 12 \\
\hline & & CSBs & 02 \\
\hline \multirow{6}{*}{ Sudeste } & Espirito Santo & CSTs & 02 \\
\hline & Minas Gerais & CSTs & 15 \\
\hline & \multirow{2}{*}{ Rio de Janeiro } & CSTs & 09 \\
\hline & & CSB & 01 \\
\hline & \multirow{2}{*}{ São Paulo } & CSTs & 48 \\
\hline & & CSBs & 02 \\
\hline \multirow{13}{*}{ Nordeste } & Alagoas & CSTs; & 02 \\
\hline & \multirow{2}{*}{ Bahia } & CSTs & 11 \\
\hline & & CSB & 01 \\
\hline & Ceará & CSTs & 07 \\
\hline & Ceará & CSB & 01 \\
\hline & Maranhão & CSTs & 03 \\
\hline & \multirow{2}{*}{ Pernambuco } & CSTs & 08 \\
\hline & & CSB & 01 \\
\hline & Piauí & CSTs & 07 \\
\hline & Rio G. do Norte & CSTs & 03 \\
\hline & Sergipe & CSTs & 02 \\
\hline & \multirow{2}{*}{ Paraíba } & CSTs & 02 \\
\hline & & CSB & 01 \\
\hline
\end{tabular}

Nota*: Tecnólogo = CST; Bacharel = CSB

Fonte: Dados da pesquisa

Quanto às categorias administrativas dos cursos presenciais ou a distância, conforme demonstra o gráfico 1, a predominância dos cursos ofertados presenciais é de iniciativa privada (com ou sem fins lucrativos), perfazendo 118 CSTs, 10 CSTs da iniciativa pública (estadual ou federal), quatro cursos de Bacharelado da iniciativa privada (sem fins lucrativos) e cinco cursos da iniciativa pública (federal), tendo esta formação um equilíbrio quantitativo maior entre as categorias pública e privada 


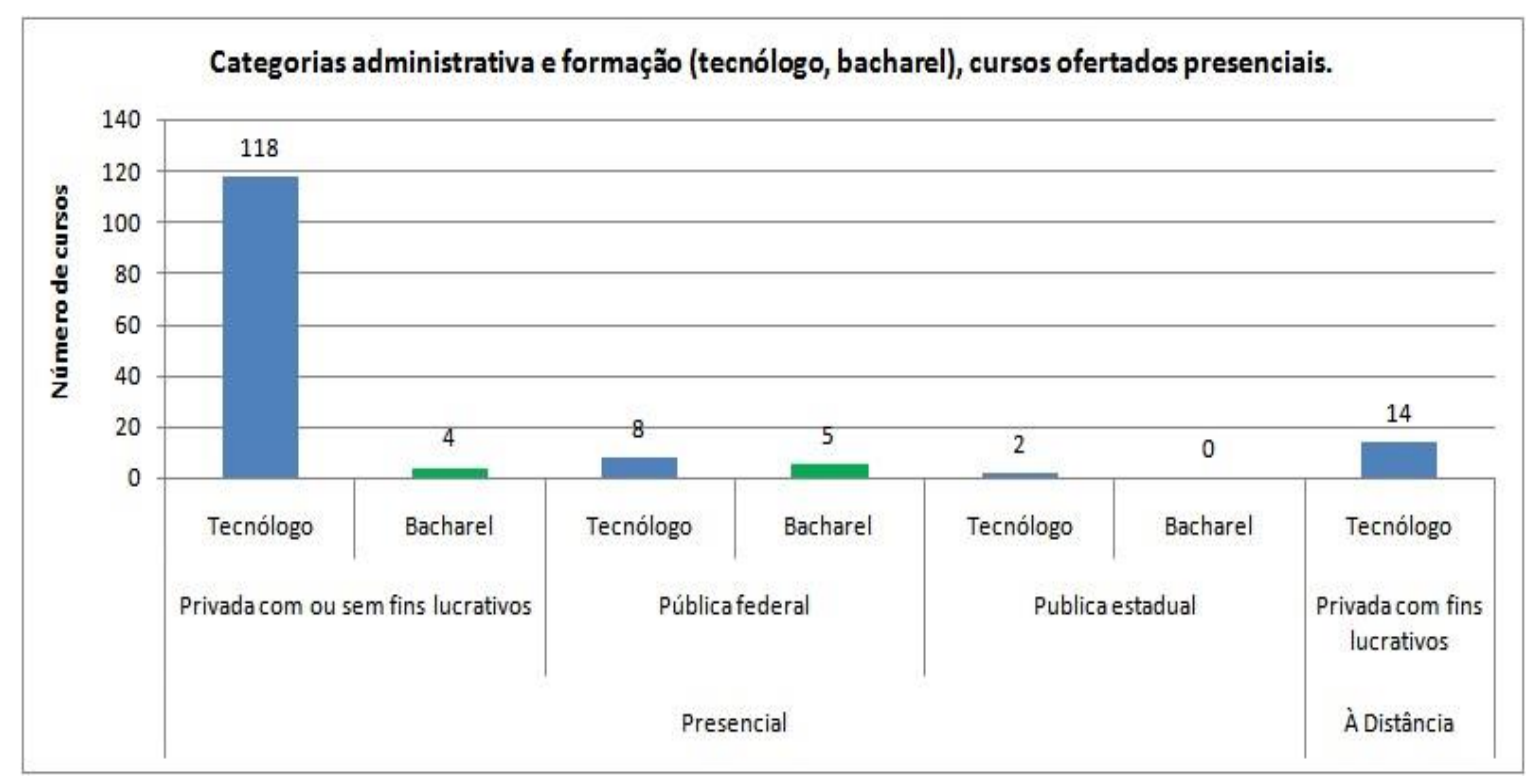

Gráfico 1 - Cursos ofertados e respectivas categorias administrativas Fonte: Brasil (2016)

Identificou-se que na modalidade a distância, considerado 14 cursos ou unidades por estado, a predominância é a formação Tecnológica e de iniciativa privada (com fins lucrativos), não havendo a formação de Bacharelado à distância.

No Brasil, independentemente da modalidade, grau ou titulação e categoria administrativa, há cursos que ofertam certificações no decorrer da formação, sendo que os critérios não são padronizados. As instituições obtêm critérios próprios para esta prática, desde que aprovados pelo MEC.

Com o objetivo de identificar quais os cursos que ofertam certificação ou titulação específica, apresenta-se no quadro 1 a quantidade de cursos por unidade federativa e as respectivas certificações.

A integralização dos cursos em Tecnologia ocorre em um período de quatro a seis semestres e, na formação de Bacharelado, de seis a oito semestres.

Ao analisar o quadro 1, na formação de Tecnólogo, percebe-se uma multiplicidade na oferta de certificação específica, em que os cursos segmentam as áreas que compõem os serviços, a operação da cozinha e o salão. Há curso que chega a ofertar quatro certificações na conclusão de uma mesma matriz curricular. 


\begin{tabular}{|c|c|c|}
\hline \multicolumn{3}{|r|}{ TITULO: TECNOLOGO EM GASTRONOMIA } \\
\hline $\mathbf{U F}$ & $\begin{array}{c}\mathbf{N}^{\mathbf{0}} \\
\text { cursos }\end{array}$ & Certificação \\
\hline $\mathrm{BA}$ & 1 & $\begin{array}{l}\text { Na conclusão do } 1^{\circ} \text { semestre = Assistente Administrativo; na conclusão } \\
\text { do } 2^{\circ} \text { semestre = Barman; na conclusão do } 3^{\circ} \text { semestre = Supervisor de } \\
\text { Cozinha e na conclusão do } 4^{\circ} \text { semestre = Maitre. } \text { - Integralização em } \\
\text { quatro e cinco semestres. }\end{array}$ \\
\hline GO & 1 & $\begin{array}{l}\text { Na conclusão do } 1^{\circ} \text { semestre = Formação Básica em Cozinha; na } \\
\text { conclusão do } 2^{\circ} \text { semestre = Sommelier, Bartender e Barista; na } \\
\text { conclusão do } 3^{\circ} \text { semestre = Formação em Confeitaria e Panificação e na } \\
\text { conclusão do } 4^{\circ} \text { semestre = Formação de Chef. - Integralização em } \\
\text { quatro semestres. }\end{array}$ \\
\hline MG & 3 & $\begin{array}{l}\text { Curso 01: Na conclusão do } 1^{\circ} \text { Ciclo=Supervisor de Gastronomia. } \\
\text { Integralização em quatro semestres. Curso 02: Na conclusão do } 1^{\circ} \text { ciclo } \\
=\text { Auxiliar } \\
\text { de Cozinha; Conclusão do } 2^{\circ} \text { ciclo = Auxiliar Técnico de Alimentos e } \\
\text { Bebidas; conclusão do } 3^{\circ} \text { ciclo = Auxiliar Técnico de Organizador de } \\
\text { Eventos Gastronômico; conclusão do } 4^{\circ} \text { ciclo = Auxiliar Técnico em } \\
\text { Panificação e Confeitaria e conclusão do } 5^{\circ} \text { ciclo = Auxiliar Técnico } \\
\text { em Gestão Gastronômica. Integralização em } 05 \text { semestres. Curso 03: } \\
\text { Na conclusão do } 1^{\circ} \text { período = Introdução à Gastronomia; } 2^{\circ} \text { período = } \\
\text { Técnicas Básicas em Gastronomia; } 3^{\circ} \text { período = Chef Júnior. } \\
\text { Integralização em quatro semestres }\end{array}$ \\
\hline PR & 1 & $\begin{array}{l}\text { Na conclusão do } 1^{\circ} \text { Ano: Modulo } 1=\text { Manipulador de Alimentos; na } \\
\text { conclusão do modulo } 2=\text { Segundo Cozinheiro e na conclusão do } 2^{\circ} \\
\text { Ano: Modulo } 03=\text { Cozinheiro. Integralização em quatro semestres. }\end{array}$ \\
\hline $\mathrm{PE}$ & 2 & $\begin{array}{l}\text { Curso 01: Na conclusão do curso = Tecnólogo em Supervisão de } \\
\text { Serviços Gastronômicos. Integralização em } 05 \text { semestres. Curso 02: } \\
\text { Na conclusão do } 3^{\circ} \text { modulo = Qualificação em Chef de Bebidas e Chef } \\
\text { de Cozinha Internacional. Integralização em quatro semestres. }\end{array}$ \\
\hline $\mathrm{RS}$ & 3 & $\begin{array}{l}\text { Curso 01: Na conclusão do } 1^{\circ} \text { módulo = Cozinheiro. Integralização em } \\
04 \text { semestres. Curso 02: Na conclusão do } 2^{\circ} \text { modulo }=\text { Patisserie; } \\
\text { conclusão do } 3^{\circ} \text { modulo = Garde Manger e na conclusão do } 4^{\circ} \text { mod.= } \\
\text { Cozinheiro profission. Integralização em } 06 \text { semestres. Curso 03: Ao } \\
\text { término dos módulos = Chef de Cozinha Nacional e Chef de Cozinha } \\
\text { Internacional. Integralização em cinco semestres. }\end{array}$ \\
\hline $\mathrm{SC}$ & 3 & $\begin{array}{l}\text { Curso 01: Na conclusão do curso = Chef. Integralização em } 04 \\
\text { sem.Curso 02: No decorrer do Curso = Manipulador de alimentos; } \\
\text { Operação em produçãa na gastronomia e Operação em serviços e bar } \\
\text { na gastr. Integralização em } 06 \text { semestres. Curso 03: Na conclusão das } \\
1^{\mathrm{a}}, 2^{\mathrm{a}} \text { e } 3^{\mathrm{a}} \text { fases = Cozinheiro, após a conclusão da } 4^{\mathrm{a}} \text { fase = Chef Partie. } \\
\text { Integralização em cinco semestres. }\end{array}$ \\
\hline
\end{tabular}

Quadro1 - Cursos que ofertam titulação/certificação específicas

(Continua...)

Fonte: Dados da pesquisa 


\begin{tabular}{|c|c|c|}
\hline \multicolumn{3}{|r|}{ TITULO: TECNOLOGO EM GASTRONOMIA } \\
\hline $\mathbf{U F}$ & $\begin{array}{c}\mathbf{N}^{\mathbf{0}} \\
\text { cursos }\end{array}$ & Certificação \\
\hline \multirow[t]{2}{*}{ SP } & 5 & $\begin{array}{l}\text { Curso 01: Na conclusão do curso = Chef. Integralização em } 04 \\
\text { semestres. Curso 02: Na conclusão do } 2^{\circ} \text { período = Cozinheiro Geral e } \\
\text { conclusão do } 3^{\circ} \text { período = Supervisor de Serviços de Alimentação e } \\
\text { Bebidas. Integralização em } 04 \text { semestres. Curso 03: Na conclusão do } \\
2^{\circ} \text { período = Cozinheiro Geral e conclusão do } 3^{\circ} \text { período = Supervisor } \\
\text { de Serviços de Alimentação e Bebidas. Integralização em 04semestres. } \\
\text { Curso 04: Na conclusão do } 2^{\circ} \text { período = Cozinheiro Geral e conclusão } \\
\text { do } 3^{\circ} \text { período = Supervisor de Serviços de Alimentação e Bebidas. } \\
\text { Integralização em quatro semestres. Curso 05: Na conclusão do curso } \\
=\text { Chef de Cozinha. Integralização em } 04 \text { semestres. } \\
\text { Curso 06: Na conclusão do } 1^{\circ} \text { semestre }=\text { Auxiliar Técnico em } \\
\text { Alimentos e Bebidas; na conclusão do } 2^{\circ} \text { semestre = Auxiliar de } \\
\text { Confeitaria e Panificação e na conclusão do } 3^{\circ} \text { semestre = Auxiliar de } \\
\text { Bartender. Integralização em quatro semestres. Curso 07: Na } \\
\text { conclusão do } 1^{\circ} \text { semestre }=\text { Profissional de Higiene e Segurança } \\
\text { Alimentar na Gastronomia; na conclusão do } 2^{\circ} \text { semestre = Profissional } \\
\text { em Gestão de Serviços de Alimentos \& Bebidas; na conclusão do } 3^{\circ} \\
\text { semestre = Profissional de Planejamento de Negócios Gastronômicos; } \\
\text { na conclusão do } 4^{\circ} \text { semestre = Profissional de Panificação e Cozinha } \\
\text { Profissional e na conclusão do } 5^{\circ} \text { semestre = Profissional da } \\
\text { Gastronomia Internacional. Integralização em cinco semestres. }\end{array}$ \\
\hline & & TITULO: BACHAREL EM GASTRONOMIA \\
\hline $\mathrm{SC}$ & 1 & $\begin{array}{l}\text { Na conclusão do } 4^{\circ} \text { período = titulação de Cozinheiro Chef } \\
\text { Internacional e } \text { Patissier. Integralização em três anos e meio. }\end{array}$ \\
\hline
\end{tabular}

Quadro1 - Cursos que ofertam titulação/certificação específicas

(Conclusão)

Fonte: Dados da pesquisa, 2016

Ao confrontar a proposta do perfil profissional apresentado pelo Catálogo Nacional de Curso Superior em Tecnologia, identifica-se que há uma diversidade excessiva de áreas de atuação nestas propostas, além de apresentar claramente que o perfil deste profissional é a atuação na produção do alimento e gestão da cozinha.

Pode-se inferir que a formação de bacharelado em gastronomia permite maior foco na gestão de empreendimentos gastronômicos, além da produção do alimento, pois o período de integralização é maior, permitindo maior diversidade de conteúdos e, consequentemente, o desenvolvimento de outras habilidade e competências para o exercício da profissão. 
A oferta de cursos ultrapassa a ação em montar uma matriz curricular composta por disciplinas fragmentadas ou engessadas, como visto em Gesser e Ranchetti (2011), principalmente pela responsabilidade dos educadores de acompanharem as mudanças que ocorrem, tanto de forma sistêmica como constante, necessitando de novos princípios organizadores.

Na contemporaneidade, é preciso a articulação de visões culturais, sociais, econômicas, permeando a teoria e prática num contexto de competências e habilidades, em forma de múltiplas dimensões, conforme sugere $\mathrm{Hu}$ (2010), em seu modelo multidimensional, que caracteriza a competência da culinária inovadora, composta por dimensões que permeiam novas propostas de formação do profissional de gastronomia.

\section{Considerações finais}

A expansão da oferta de cursos é uma realidade e o aumento de profissionais aptos a transformar o alimento em arte, com técnicas e métodos eficientes, além de transformar os serviços, dos mais simples aos mais complexos em valores custo benefício, torna o mercado mais exigente com pessoas cada vez mais criteriosas pela busca de qualidade.

Atualmente, o setor de restauração, identificado como empreendimento na área de alimentos e bebidas, obtém um papel importantíssimo para a economia, a cultura e o turismo. A Gastronomia tornou-se uma arte que vai além do cozinhar, elevou-se ao status de tornar o alimento um produto de inúmeras vertentes, necessitando de um conhecimento multidisciplinar, aliando competências e habilidades imprescindíveis para sua atuação.

Torna-se, portanto, imprescindível que as titulações e os perfis profissionais propostos pelas instituições de ensino estejam alinhados com a necessidade do mercado de trabalho, pois o segmento requer uma atuação que permeia desde a área da produção até a gestão, seja ela em uma cozinha ou em um empreendimento. As suas modalidades e graus devem ser respeitados, de acordo com a atuação deste futuro profissional.

A oferta de cursos de Gastronomia vem crescendo significativamente, fato que deve ser minuciosamente monitorado, pois já se obtive exemplos como na área de Turismo visto que, em um período de 10 anos, houve uma explosão da oferta de cursos superiores e as consequências foram desastrosas, tanto para as instituições, onde muitos cursos fecharam como para os 
formados, que tiveram suas profissões comprometidas pela qualidade da formação e a própria absorção ou não do mercado

A educação superior, embora tenha atingido uma evolução em sua política, ainda traz resquícios dominadores da classe governamental. É necessário acompanhar novos conceitos, novas tecnologias e, assim, formar pessoas mais críticas, responsáveis e com formação inter e transdisciplinares.

Os currículos, em um viés crítico, podem ser considerados um registro ou um instrumento como um campo cultural, onde saberes e práticas disputam por hegemonia. Aponta-se possíveis transformações nas maneiras de abordagem dos conteúdos, visando a modificação dos conteúdos ensinados.

Novos paradigmas e modelos parecem ser inevitáveis. As instituições de ensino precisam formar pessoas capazes e aptas para uma intervenção social. Uma nova forma de apropriação de saberes, em que a capacidade de realizar bem uma determinada tarefa é relacionada à competência.

\section{Referências}

BETANCOURT-RAMIREZ, J. B.; ALDANA-DE-VEGA, L.; GOMEZ-BETANCOURT, G. Serviço, ambiente e qualidade de restaurantes em Bogotá. Estudo comparativo de empresas familiares e empresas não-familiares. Entramado [online], v. 10, n. 2, p. 60-74, 2014.

BIRDIR, K.; PEARSON, T. E. Research chefs' competencies: A Delphi approach.

International Journal of Contemporary Hospitality Management, v, 12, n. 3, p. 205-209. Disponível em: <doi:10.1108/0959611001030998>. Acesso em: 2 out. 2016.

BOYATZIS, R. E. The competent manager: a model for effective performance. New York: Wiley, 1982.

BRASIL. Ministério da Educação. Apresentação. 2014. Disponível em: $<$ http://portal.mec.gov.br/index.php?Itemid=504\&id=12262\&option=content $\&$ view=article $>$. Acesso em: 13 jan. 2014.

BRASIL. Ministério da Educação. Catálogo nacional de cursos superiores de tecnologia. Brasília: MEC, 2016. Disponível em: <download\&alias=44501-cncst-2016-3edcpdf\&category_slug=junho-2016-pdf\&Itemid=30192>. Acesso em: 2 out. 2017.

BRASIL. Ministério da Educação. Sistema E-MEC. 2015. Disponível em: <http:// www.mec.gov.br>. Acesso em: 11 nov. 2015. 
ANJOS, F; A.; CABRAL, S. R.; HOSTINS, R. C. L. O Cenário da Formação (...). Revista Hospitalidade. São Paulo, volume 14, n.01,

GESSER, V.; RANGHETTI, D. S. O currículo no ensino superior: princípios epistemológicos para um design contemporâneo. Revista e-Curriculum, São Paulo, v. 7, n. 2, p. 1-23, ago. 2011. Disponível em: https://revistas.pucsp.br/index.php/curriculum/article/viewFile/6775/4902>. Acesso em: 8 jan. 2016.

HEGARTY, J. A. Culinary science and technology-designed to meet the needs of graduates seeking carees as foodservice specialists, caters, andlor restaurateurs? Journal of Culinary Science \& Technology, v. 4, n. 2/3, p. 1-5, 2005. Disponível em:

<http://dx.doi.org/10.1300/J385v04n02_01>. >, Acesso em: 25 ago. 2013.

HU, M. L. M. Discovering culinary competency: na innovative approach. Journal of Hospitality, Leisure, Sport and Tourism Education, v.9, n. 1, p. 65-72, 2010.

KRAUSE, R. K. Uma reflexão sobre o ensino da gastronomia no Brasil. In: RUSCHMANN, D. V. M.; TOMELIN, C. A. (Org.). Turismo, ensino e práticas interdisciplinares. São Paulo: Manole, 2013. Cap.12, p. 203.

RUBIM, R. E.; REJOWSKI, M. O ensino superior da gastronomia no Brasil: análise da regulamentação, da distribuição e do perfil geral de formação (2010-2012). Revista Turismo Visão e Ação, v. 15, n. 2, p. 166-184, maio/ago 2013, Disponível em:

<www.univali.br|revistaturismo>. Acesso em: 15 dez. 2013.

SANTICH, B. The study of gastronomy and its relevance to hospitality education and training. International Journal of Hospitality Management, v. 23, n. 1, p. 15-24, 2004.

ZOPIATIS, A. Is it art or science? Chef's competencies for success. International Journal of Hospitality Management, v. 29, n. 3, p. 459-467, 2010. Disponível em: < 10.1016/j.ijhm.2009.12.003>. Acesso em: 22 ago. 2013.

Recebido em: 12/03/2017

Revisto em: 13/08//2017

Aprovado em: 25/08/2017 